\title{
Prevalence and Associated Clinical Factors of GERD (Gastro-Esophageal Reflux Disease) in Ischemic Stroke Patients
}

\author{
Michiya Igase ${ }^{1 *}$, Katsuhiko Kohara ${ }^{1}$, Keiji Igase ${ }^{2}$, Shiro Yamashita ${ }^{3}$, Mutsuo Fujisawa ${ }^{3}$, Ryosuke Katagi ${ }^{3}$, Tetsuro Miki ${ }^{1}$
}

${ }^{1}$ Department of Geriatric Medicine, Ehime University Graduate School of Medicine, Japan

${ }^{2}$ Department of Neurosurgery, Washokai Sadamoto Hospital, Japan

${ }^{3}$ Ryotenkai Katagi Neurosurgery, Japan

\begin{abstract}
Purpose: Aspirin is protective against ischemic stroke, but its use is a significant risk factor for gastro-esophageal reflux disease (GERD). We investigated the prevalence and associated clinical factors of GERD in ischemic stroke patients treated with aspirin.
\end{abstract}

Methods: We recruited 116 ischemic stroke outpatients who were receiving aspirin. Sixteen patients who had received proton pump inhibitors or $\mathrm{H} 2$ receptor antagonists within the previous month were excluded. The presence of GERD was defined using the GerdQ questionnaire, with a score of 8 or higher considered positive for GERD. Logistic regression analysis was conducted using variables which exhibited a significant correlation coefficient on two-group comparison as factors, with the presence or absence of GERD as the dependent variable.

Results: Mean age of the 100 patients analyzed was $69.3 \pm 8.9$ years. The prevalence of GERD was $28 \%$. Mean BW of patients with GERD was significantly higher than of those without GERD $(P=0.02)$. The proportion of patients receiving angiotensin II receptor blockers (ARBs) was significantly lower in the GERD group ( $P=0.04)$. In contrast, no significant difference was seen in the proportion of patients receiving calcium channel blockers (CCBs). Multivariable logistic regression analysis showed that ARB disuse and increased BW were independent predictors of GERD.

Conclusions: The prevalence of GERD was $28 \%$ in ischemic stroke patients treated with aspirin. Increased BW as well as ARBs disuse was independent risk factors of GERD. With all these factors, ARBs appear to be better suited than CCBs for use in patients with ischemic stroke with regard to the prevention of GERD. A comprehensive understanding of the relationship between ARBs and GERD prevalence awaits additional studies in a larger number of patients.

Keywords: GERD; Ischemic stroke; GerdQ; ARB; Protection

\section{Introduction}

Gastro-esophageal reflux disease (GERD) is defined as the condition that develops when the reflux of stomach contents causes troublesome symptoms or complications, including reflux esophagitis (RE) [1], and is common in daily clinical practice [2]. Although aspirin is frequently used as an antiplatelet agent in patients with ischemic stroke [3], owing to its ability to reduce overall stroke rates in secondary stroke prevention [4], it has recently been considered a risk factor for GERD symptoms $[5,6]$.

The association between aspirin and GERD is well established, but few studies have examined the relationship between oral aspirin and GERD in ischemic stroke patients.

Here, we investigated the prevalence and associated clinical factors of GERD in patients with ischemic stroke patients treated with aspirin.

\section{Methods}

The subjects were ischemic stroke patients who had been treated in the outpatient clinic of the Ryotenkai Katagi Neurosurgery in April and May 2012. Enrollment was limited to ischemic stroke patients aged $>20$ years from whom written informed consent was obtained. All study patients underwent antithrombotic low-dose aspirin therapy (81-100mg/day) and gastric coating agents. Patients who had received proton pump inhibitors or $\mathrm{H} 2$ receptor antagonists within 1 month or who had life-threatening complications were excluded. Patients were met prior to GerdQ questionnaire by the researcher to discuss the study, obtain informed consent from patients willing to take part, and scheduled an interview. The study was conducted in accordance with the principles of the Declaration of Helsinki.

\section{GerdQ questionnaire}

GerdQ is a well-documented questionnaire which was developed under a rigorous evidence-based approach $[7,8]$. In one study, patients with a GerdQ score of 8 or higher were regarded as having GERD, and a clinical approach based on this classification was shown to provide lower health care costs than an empirical approach without any loss of efficacy [9]. Following these findings, GerdQ is now considered a useful tool for the diagnosis of GERD without the need for specialist referral or endoscopy (gastroenterological evaluation).

\section{Study design}

After obtaining written informed consent, we enquired about GERD symptoms using the GerdQ questionnaire (Table 1). In brief, GerdQ scores the frequency of six items: 1) heartburn, 2) regurgitation,

*Corresponding author: Michiya Igase, Department of Geriatric Medicine, Ehime University Graduate School of Medicine, Toon City, Ehime 791-0295, Japan, Tel: +81-89-960-5851; Fax: +81-89-960-5852; E-mail: migase@m.ehime-u.ac.jp

Received January 18, 2013; Accepted April 20, 2013; Published April 25, 2013

Citation: Igase M, Kohara K, Igase K, Yamashita S, Fujisawa M, et al. (2012) Prevalence and Associated Clinical Factors of GERD (Gastro-Esophageal Reflux Disease) in Ischemic Stroke Patients. J Neurol Neurophysiol S8: 004 doi:10.4172/2155-9562.S8-004

Copyright: (C) 2012 Igase $\mathrm{M}$, et al. This is an open-access article distributed unde the terms of the Creative Commons Attribution License, which permits unrestricted use, distribution, and reproduction in any medium, provided the original author and source are credited. 


\begin{tabular}{|c|c|c|c|c|c|}
\hline \multirow{2}{*}{\multicolumn{2}{|c|}{ Question }} & \multicolumn{4}{|c|}{ Frequency score (points) for symptom } \\
\hline & & \multirow{2}{*}{$\begin{array}{c}0 \text { day } \\
0\end{array}$} & \multirow{2}{*}{$\begin{array}{c}1 \text { day } \\
1\end{array}$} & \multirow{2}{*}{$\begin{array}{c}2-3 \text { days } \\
2\end{array}$} & \multirow{2}{*}{$\begin{array}{c}\text { 4-7 days } \\
3\end{array}$} \\
\hline & $\begin{array}{l}\text { How often did you have a burning } \\
\text { feeling behind your breastbone } \\
\text { (heartburn)? }\end{array}$ & & & & \\
\hline 2. & $\begin{array}{l}\text { How often did you have stomach } \\
\text { contents (liquid or food) moving } \\
\text { upwards to your throat or mouth } \\
\text { (regurgitation)? }\end{array}$ & 0 & 1 & 2 & 3 \\
\hline 3. & $\begin{array}{l}\text { How often did you have pain in the } \\
\text { centre of the upper stomach? }\end{array}$ & 3 & 2 & 1 & 0 \\
\hline 4. & How often did you have nausea? & 3 & 2 & 1 & 0 \\
\hline & $\begin{array}{l}\text { How often did you have difficulty } \\
\text { getting a good night's sleep } \\
\text { because of your heartburn and/or } \\
\text { regurgitation? }\end{array}$ & 0 & 1 & 2 & 3 \\
\hline & $\begin{array}{l}\text { How often did you take additional } \\
\text { medication for your heartburn and/ } \\
\text { or regurgitation, other than what } \\
\text { the physician told you to take? }\end{array}$ & 0 & 1 & 2 & 3 \\
\hline
\end{tabular}

Table 1: GerdQ questionnaire.

3) dyspepsia, 4) nausea, 5) sleep disturbance, and 6) need for over-thecounter (OTC) treatment during the past 7 days using a 4-point scale with a score range of 0 to 3 ( $0=0$ days/week; $1=1$ day/week; $2=2-3$ days/ week; and 3=4-7 days/week). In accordance with previous reports, patients with a GerdQ score of 8 or higher of a maximum possible score of 18 were regarded as having GERD (7-9). Endoscopy was not performed. Medical records and drug history were retrospectively surveyed to clarify factors involved in GERD.

\section{Survey items}

Age, gender, height, body weight (BW), type of stroke (atherothrombotic, lacunar, cardioembolic, and transient ischemic attack), systolic blood pressure (SBP), diastolic blood pressure (DBP), and pulse rate (PR) were recorded. The presence or absence of hypertension (use of antihypertensive agents, systolic blood pressure $>140 \mathrm{mmHg}$, or diastolic blood pressure $>90 \mathrm{mmHg}$ before stroke onset); dyslipidemia (use of lipid-lowering agents; or serum levels of TC $>220 \mathrm{mg} / \mathrm{dL}, \mathrm{TG}>150 \mathrm{mg} / \mathrm{dL}, \mathrm{LDL}-\mathrm{C}>140 \mathrm{mg} / \mathrm{dL}$ and/or HDL-C $<40$ $\mathrm{mg} / \mathrm{dL}$ ); type 2 diabetes mellitus (use of oral hypoglycemic agents or insulin, fasting blood glucose $>126 \mathrm{mg} / \mathrm{dL}$, or glycosylated hemoglobin level $>6.5 \%$ ); and smoking habit (smoking during the preceding 12 months) was determined.

Information on concomitant medication including antihypertensive agents (angiotensin II receptor blockers, ARBs; calcium channel blockers, CCBs; diuretics; angiotensin-converting enzyme inhibitors, ACEIs; beta blockers and alpha blockers), lipidlowering agents (hydroxymethylglutaryl coenzyme A reductase inhibitors, statins; ezetimibe; eicosapentaenoic acid, EPA), glucoselowering agents (sulfonylurea; dipeptidyl peptidase 4 inhibitors, DPP4 inhibitors; thiazolidinedione derivatives, TDs; anda-glucosidase inhibitors, $\alpha$-GIs) and insulin was collected.

\section{Statistical analysis}

Continuous values were expressed as the mean \pm SD. Subjects were divided into two groups using a GerdQ score of 8 points as cut-off. The significance of differences in mean values and proportions was tested using Student's t-test for continuous variables and the chi-squared test for dichotomous variables. This was followed by a multivariable logistic regression analysis including those variables with a $p<0.1$ in the univariate analysis. A two-tailed $\mathrm{P}$ value of $<0.05$ was regarded as significant. For analysis, we employed SPSS version 13.0 (SPSS Inc., Chicago, IL).

\section{Results}

A total of 100 patients were analyzed (Table 2). Mean patient age was $69.3 \pm 8.9$ years, and $59 \%$ (59) were male. Twenty-eight patients (28\%) had GERD (GerdQ score $\geq 8$ ). Clinical details of patients with and without GERD are compared in Table 2. Mean BW of patients with GERD was significantly higher than of those without GERD ( $\mathrm{P}=$ 0.02). The proportion of patients receiving ARBs ( $46 \%$ vs. $69 \%$; $=0.04$ ) was significantly lower in the GERD group. In contrast, no significant difference was seen in the proportion of patients receiving CCBs $(68 \%$ vs. $75 \% ; \mathrm{P}=0.47$ ), while the proportion prescribed lipid lowering agents or oral glucose-lowering agents in the two groups was similar.

Multivariable logistic regression analysis was done using GERDassociated variables which had been found significant or marginally significant in the previous analysis (Table 2), with the presence or absence of GERD as the dependent variable. Results showed that BW (odds ratio (OR) 1.086; 95\% confidence interval (CI): 1.020-1.157; P $<0.05$ ) and ARB use (OR 0.302; 95\% CI: 0. 112-0. 819; P < 0.05) were associated with the presence of GERD. SBP and diuretics uses were not significantly associated (Table 3 ).

\section{Discussion}

In this study, the prevalence of GERD in patients with ischemic

\begin{tabular}{|l|l|l|l|l|}
\hline Investigation item & $\begin{array}{l}\text { All patients } \\
(\mathrm{N}=100)\end{array}$ & $\begin{array}{l}\text { GERD }(+) \\
(\mathrm{n}=28)\end{array}$ & $\begin{array}{l}\text { GERD(-) } \\
(\mathrm{n}=72)\end{array}$ & P-value \\
\hline Age(year) & $69.3 \pm 8.9$ & $66.9 \pm 9.4$ & $70.3 \pm 8.6$ & 0.88 \\
\hline Gender(male/female) & $59 / 41$ & $17 / 11$ & $42 / 30$ & 1.00 \\
\hline Height(cm) & $159.3 \pm 7.7$ & $160.8 \pm 8.5$ & $158.7 \pm 7.3$ & 0.24 \\
\hline Body weight(kg) & $62.8 \pm 10.1$ & $67.8 \pm 12.8$ & $60.2 \pm 9.1$ & 0.02 \\
\hline Stroke type(A/L/C/T) & $34 / 49 / 14 / 3$ & $11 / 13 / 2 / 2$ & $23 / 36 / 12 / 1$ & 0.27 \\
\hline SBP(mmHg) & $129.0 \pm 13.1$ & $127.4 \pm 10.6$ & $129.6 \pm 13.9$ & 0.06 \\
\hline DBP(mmHg) & $75.0 \pm 10.3$ & $74.8 \pm 10.5$ & $75.1 \pm 10.3$ & 0.99 \\
\hline PR(/min) & $69.7 \pm 10.8$ & $70.5 \pm 10.4$ & $69.4 \pm 11.0$ & 0.46 \\
\hline Hypertension (\%) & $88(88)$ & $23(82)$ & $65(90)$ & 0.31 \\
\hline ARBs (\%) & $63(63)$ & $13(46)$ & $50(69)$ & 0.04 \\
\hline CCBs (\%) & $73(73)$ & $19(68)$ & $54(75)$ & 0.47 \\
\hline Diuretics (\%) & $15(15)$ & $1(4)$ & $14(19)$ & 0.06 \\
\hline ACEls (\%) & $5(5)$ & $2(7)$ & $3(4)$ & 0.62 \\
\hline Beta blockers (\%) & $7(7)$ & $2(7)$ & $5(7)$ & 1.00 \\
\hline Alfa blockers (\%) & $7(7)$ & $2(7)$ & $5(7)$ & 1.00 \\
\hline Dyslipidemia (\%) & $73(73)$ & $13(64)$ & $55(76)$ & 0.32 \\
\hline Statins (\%) & $71(71)$ & $19(68)$ & $52(72)$ & 0.81 \\
\hline Ezetimib (\%) & $2(2)$ & $0(0)$ & $2(3)$ & 1.00 \\
\hline EPA (\%) & $12(12)$ & $1(4)$ & $11(15)$ & 0.17 \\
\hline DM (\%) & $38(38)$ & $14(50)$ & $24(33)$ & 0.17 \\
\hline SUs (\%) & $13(13)$ & $4(14)$ & $9(13)$ & 0.75 \\
\hline DPP4 inhibitors (\%) & $24(24)$ & $10(36)$ & $14(19)$ & 0.12 \\
\hline TDs (\%) & $13(13)$ & $4(14)$ & $9(13)$ & 0.75 \\
\hline a-Gls (\%) & $7(7)$ & $2(7)$ & $5(7)$ & 1.00 \\
\hline Insulin (\%) & $2(2)$ & $1(4)$ & $1(1)$ & 0.48 \\
\hline Current smoking & $5(5)$ & $0(0)$ & $5(7)$ & 0.32 \\
\hline Values are mean \pm & & & & \\
\hline
\end{tabular}

Values are mean \pm standard deviation. Stroke type $(A / L / C / T)$, atherothrombotic stroke/lacunar stroke, cardioembolic stroke/TIA; SBP, systolic blood pressure; $\mathrm{DBP}$, diastolic blood pressure; $\mathrm{PR}$, pulse rate; ARBs, angiotensin receptor blockers; CCBs, calcium channel blockers; ACEIs, angiotensin converting enzyme inhibitors; SUs, sulfonylureas; DPP4 inhibitors, dipeptidyl Peptidase-4 inhibitors; TDs, thiazolidine derivatives; $\alpha-G l s$, alfa-glycosidase inhibitors. 


\begin{tabular}{|c|c|c|c|}
\hline \multirow{2}{*}{ Odds ratio } & \multicolumn{2}{|c|}{$95 \%$ confidence interval } \\
\cline { 3 - 4 } & & Lower limit & Upper limit \\
\hline Body weight & $1.086^{*}$ & 1.020 & 1.157 \\
\hline SBP & 0.965 & 0.925 & 1.008 \\
\hline ARBs use & $0.302^{*}$ & 0.112 & 0.819 \\
\hline Diuretics use & 0.314 & 0.059 & 1.664 \\
\hline
\end{tabular}

Odds ratios adjusted for age and sex.

${ }^{*} \mathrm{P}<0.05$, SBP, systolic blood pressure; ARBs, angiotensin receptor blockers.

Table 3: Odds ratios and 95\% confidence intervals for independent predictors of GERD, identified by multivariable logistic regression analysis.

stroke as identified using the GerdQ questionnaire was $28 \%$, which is higher than the approximately 10-20\% prevalence previously reported in the general population $[2,10]$. This increase can be ascribed to the use of antiplatelet agents in these patients despite use of gastric coating agents. Ercelep et al. demonstrated that antiplatelet therapy was an independent risk factor for GERD symptoms [11]. Moreover, 16 patients were excluded from the present study owing to their use of proton pump inhibitors or $\mathrm{H} 2$ receptor antagonists for GERD symptoms within the previous month; inclusion of these patients would have increase the prevalence of GERD to approximately $38 \%$. These findings highlight the need to protect patients with ischemic stroke from the development of GERD.

Our finding that BW was positively associated with the presence of GERD is consistent with a previous finding of a significant association with a body mass index (BMI) over 30 [11]. Recently, Niigaki et al. demonstrated that metabolic syndrome, a cluster of metabolic risk factors, was a significant predictive factor for the prevalence of GERD [12]. In contrast to our findings, however, they also found that subjects undergoing treatment for dyslipidemia and diabetes mellitus were at decreased risk of GERD. One reason for this difference might be the relatively young age of their participants, with a mean of 52 years versus our present subjects, at 69 years.

Hypertension is the single most important modifiable risk factor for recurrent stroke. Although blood pressure control is an important intervention for secondary stroke prevention [13], subjects undergoing treatment for hypertension are at increased risk of GERD [14]. The selection of antihypertensive drugs therefore requires consideration of digestive system function. In our subjects, use of either ARB or CCB was high, at $63 \%$ and $73 \%$, respectively, while $52 \%$ received combination therapy. Among antihypertensive drugs, ARBs are considered to have greater efficacy in stroke prevention that CCB [15]. Generally, agents that relax the lower esophageal sphincter (LES) can induce GERD symptoms; CCBs in particular may decrease LES pressure and lead to the onset of GERD. In this regard, Horikawa et al. found that the prevalence of GERD was correlated with the proportion of patients treated with $\mathrm{CCB}$ on univariate correlation analysis, but found no significant association on logistic regression analysis, as in the present study [14].

The most intriguing result of our study was that the antihypertensive agent ARB was negatively associated with the presence of GERD. Multiple logistic regression analysis revealed that the combination of ARBs had a significant positive impact on endoscopic healing (OR 3.9, 95\% CI 1.411-10.903), whereas no significant positive relationship was seen for other antihypertensive drugs such as CCBs.

Consistent with this finding, Miwa investigated endoscopic findings before and after treatment in 454 RE patients who received PPI therapy for 8 weeks and demonstrated that concomitant use of ARBs promoted endoscopic healing of RE in these patients [16]. Recently, Brzozowski et al. reported a novel concept in the mechanism of protection of gastric mucosa by ARB [17]. They demonstrated a gastro-protective role of angiotensin-(1-7), an ANG II metabolite produced in the breakdown of ARBs. Angiotensin-(1-7) is produced in excessive amounts in the gastric mucosa and exhibits potent gastro-protective activity against gastric lesions. These findings provide evidence to support our results that ARB act as a protector to occurrence of GERD. ARBs appear to be better suited than CCBs for use in patients with ischemic stroke with regard to the prevention of GERD.

\section{Limitations}

Several limitations of the study warrant mention. First, sample size was small, which considerably limits the conclusions which can be drawn the data. A large number of prospective studies are required to confirm the result. Second, because there are no reports indicating association between GERD and ARB, it is not clear how ARB might protect the patients from GERD. Third, because the study was conducted under a cross-sectional design, we were unable to analyze the importance of the ARB-induced decrease in GERD. A comprehensive understanding of the relationship between ARBs and GERD prevalence awaits additional studies in a larger number of patients. One of ongoing study would yield some important findings with regard to the prevalence of gastrointestinal complications and related risk factors for low-dose aspirin users [18].

\section{Acknowledgements}

M.I. performed the research, M.I and K.I collected and analysed the data, M.I. designed the research study and wrote the paper, and K.K., S.Y., M.F., R.K., and T.M. contributed to the design of the study.

\section{References}

1. Vakil N, van Zanten SV, Kahrilas P, Dent J, Jones R (2006) Global Consensus Group. The Montreal definition and classification of gastroesophageal reflux disease: a global evidence-based consensus. Am J Gastroenterol 101: 19001920.

2. Dent J, El-Serag HB, Wallander MA, Johansson S (2005) Epidemiology of gastro-oesophageal reflux disease: a systematic review. Gut 54: 710-717.

3. Alberts MJ (2011) Antithrombotic therapy for secondary stroke prevention Continuum (Minneap Minn) 17: 1255-1266.

4. Ruszniewski $P$, Soufflet $C$, Barthélémy $P$ (2008) Nonsteroidal anti-inflammatory drug use as a risk factor for gastro-oesophageal reflux disease: an observational study. Aliment Pharmacol Ther 28: 1134-1139.

5. Antithrombotic Trialists' Collaboration (2002) Collaborative meta-analysis of randomised trials of antiplatelet therapy for prevention of death, myocardial infarction, and stroke in high risk patients. BMJ 324: 71-86.

6. Leys D, Balucani C, Cordonnier C (2009) Antiplatelet drugs for ischemic stroke prevention. Cerebrovasc Dis 27: 120-125.

7. Jones R, Junghard O, Dent J, Vakil N, Halling K, et al. (2009) Development of the GerdQ, a tool for the diagnosis and management of gastro-oesophageal reflux disease in primary care. Aliment Pharmacol Ther 30: 1030-1038.

8. Ponce J, Garrigues V, Agréus L, Tabaglio E, Gschwantler M, et al. (2012) Structured management strategy based on the Gastro-oesophageal Reflux Disease (GERD) Questionnaire (GerdQ) vs. usual primary care for GERD pooled analysis of five cluster-randomised European studies. Int J Clin Pract 66: 897-905

9. Jonasson C, Moum B, Bang C, Andersen KR, Hatlebakk JG (2012) Randomised clinical trial: a comparison between a GerdQ-based algorithm and an endoscopy-based approach for the diagnosis and initial treatment of GERD. Aliment Pharmacol Ther 35: 1290-1300.

10. Furukawa N, Iwakiri R, Koyama T, Okamoto K, Yoshida T, et al. (1999) Proportion of reflux esophagitis in 6010 Japanese adults: prospective evaluation by endoscopy. J Gastroenterol 34: 441-444.

11. Ercelep OB, Caglar E, Dobrucali A (2012) The prevalence of gastroesophageal reflux disease among hospital employees. Dis Esophagus. 
Citation: Igase M, Kohara K, Igase K, Yamashita S, Fujisawa M, et al. (2012) Prevalence and Associated Clinical Factors of GERD (Gastro-Esophageal Reflux Disease) in Ischemic Stroke Patients. J Neurol Neurophysiol S8: 004. doi:10.4172/2155-9562.S8-004

12. Niigaki M, Adachi K, Hirakawa K, Furuta K, Kinoshita Y (2013) Association between metabolic syndrome and prevalence of gastroesophageal reflux disease in a health screening facility in Japan. J Gastroenterol 48: 463-472.

13. Qureshi Al, Sapkota BL (2011) Blood pressure reduction in secondary stroke prevention. Continuum (Minneap Minn) 17: 1233-1241.

14. Horikawa A, Ishii-Nozawa R, Ohguro M, Takagi S, Ohtuji M, et al. (2009) Prevalence of GORD (gastro-oesophageal reflux disease) in Type 2 diabetes and a comparison of clinical profiles between diabetic patients with and without GORD. Diabet Med 26: 228-233.

15. Schrader J, Lüders S, Kulschewski A, Hammersen F, Plate K, et al. (2005) Morbidity and Mortality After Stroke, Eprosartan Compared with Nitrendipine for Secondary Prevention: principal results of a prospective randomized controlled study (MOSES). Stroke 36: 1218-1226.
16. Miwa H, Hongo M, Kusano M, J-FAST Group (2012) Combination of angiotensin II receptor blockers promotes proton pump inhibitor-based healing of reflux esophagitis. J Gastroenterol 47: 249-255.

17. Brzozowski T, Ptak-Belowska A, Kwiecien S, Krzysiek-Maczka G, Strzalka $M$, et al. (2012) Novel concept in the mechanism of injury and protection of gastric mucosa: role of renin-angiotensin system and active metabolites of angiotensin. Curr Med Chem 19: 55-62.

18. Origasa H, Goto S, Shimada K, Uchiyama S, Okada Y, et al. (2011) MAGIC Investigators. Prospective cohort study of gastrointestinal complications and vascular diseases in patients taking aspirin: rationale and design of the MAGIC Study. Cardiovasc Drugs Ther 25: 551-560.

This article was originally published in a special issue, Stroke:

Cerebrovascular Accident handled by Editor(s). Dr. David Della Morte,

University of Miami, USA 